\title{
Single-centre all-comers registry reveals promising long-term clinical results of the Endeavor ${ }^{\mathrm{TM}}$-Stent
}

\author{
Klaus Hertting, Agneta Wieneke, Daniel Hausmann, Claudia Zeiler, Christian Pott, Werner Raut
}

Department of Cardiology, Krankenhaus Buchholz, Buchholz, Germany

Email: hertting@hotmail.com

Received 20 February 2012; revised 9 March 2012; accepted 27 March 2012

\begin{abstract}
Background: To evaluate the safety and efficacy of the Endeavor ${ }^{\mathrm{TM}}$-Stent (Medtronic Corp., USA) in daily practice. Material and Methods: Data come from a prospective single-centre registry. Between 2005 and 2007 all patients, who received at least one Endeavor ${ }^{\mathrm{TM}}$ coronary stent, were included into a registry. Patients were contacted after 12 and 24 - 36 months. Results: 326 patients ( 97 females, mean age $(67.5 \pm 10.3)$ years) were included. From these patients $137(42 \%)$ had a 3-vessel disease, 96 (29\%) presented with myocardial infarction $\leq 72 \mathrm{hrs}, 19(6 \%)$ with a left ventricular ejection fraction $<25 \%$. In summary, 379 lesions $(\mathbf{5 0} \%$ type $\mathrm{B} 2,23 \%$ type $\mathrm{C}$, mean lesion length $(20.2 \pm 10.0)$ $\mathrm{mm}$, mean reference vessel diameter $(3.0 \pm 0.4) \mathbf{~ m m})$ were treated with Endeavor ${ }^{\mathrm{TM}}$-Stents. Per patient, 0.4 \pm 0.7 bare metal stents were implanted. Median follow-up time was 35.3 months, during follow-up 165 patients $(50.6 \%)$ had repeated angiography. After 12 (24) months overall mortality was $5.8 \%(7.3 \%)$, cardiac mortality $3.1 \%(3.5 \%)$, myocardial infarction rate $1.5 \%(4.1 \%)$, target-vessel revascularization rate $8.7 \%(12.4 \%)$, target-lesion revascularization rate $6.1 \%(8.4 \%)$, and cumulative MACE-rate $14.1 \%$ $(21.9 \%)$. In total, 2 definite or likely stent-thromboses $(0.6 \%)$ occurred during follow-up. Logistic regression revealed the treatment of saphenous vein grafts and aorto-coronary ostial lesions as risk factors for target lesion revascularization. Conclusion: The Endeavor ${ }^{\mathrm{TM}}$ Stent is a safe and effective drug-eluting stent in the treatment of daily-life coronary patients. Treatment of vein grafts and aorto-coronary ostial lesions appear to be associated with a higher need for re-interventions.
\end{abstract}

Keywords: Zotarolimus; Restenosis; Drug-Eluting Stent

\section{INTRODUCTION}

The use of drug-eluting stents (DES) is daily routine in the interventional treatment of coronary artery disease. The Endeavor ${ }^{\mathrm{TM}}$-Stent (Medtronic Corp., USA) represents a second-generation drug-eluting stent, based on a chromium-cobalt-nickel alloy carrier stent, a phosphorylcho-line polymer, and zotarolimus as antiproliferative drug [1]. When then stent received CE-mark in 2005 only limited yet promising data of the stent was available from the Endeavor I and Endeavor II trials with a limited follow-up period $[1,2]$.

We thus thought to create a registry to evaluate the Endeavor ${ }^{\mathrm{TM}}$ stent in a "real-life" clinical setting.

\section{MATERIAL AND METHODS}

This registry represents single centre data of a community hospital without on-site cardiac surgery but with 24hours on-call service. Between September 2005 and September 2007 we included all patients with an intracoronary implantation of at least one Endeavor ${ }^{\mathrm{TM}_{-}}$Stent in this registry containing demographical, clinical and interventional data. There were no exclusion criteria. Interventions were performed by 4 experienced cardiologists. Treatment of other coronary lesions, the use of material and medication were left to the operators' discretion. Patients were followed-up after 12 and after 24 36 months using a written questionnaire asking for clinical status, cardiac complaints, clinical events and medication record. If necessary, this data has been completed by telephone contact or by contacting the family doctor or cardiologist. If patients could not be contacted then their last hospital or family-doctor contact was set as last follow-up date. Primary endpoints were target lesion revascularization (TLR) and major adverse cardiovascular events (MACE), i.e. the combined endpoint of death, myocardial infarction and target vessel revascularization (TVR). All patients gave informed consent for taking part in this registry.

\subsection{Angiographical Analysis}

All angiographies have been reviewed by at least two interventional cardiologists in a non-blinded fashion. 
Measurements were made using biplane quantitative coronary analysis (QCA). Lesions have been classified using the American Heart Association (AHA) and American College of Cardiology (ACC) classification [3]. Routine follow-up angiographies had not been scheduled, only if clinically indicated. Left ventricular ejection fraction (LVEF) has been measured using biplane left ventriculography or biplane echocardiography when ventriculography was not available.

\subsection{Statistical Analysis}

Statistics have been performed using SPSS V11.5 (SPSS Co., Chicago, Illinois, USA). Follow-up time intervals are presented as median and 25\%- and 75\%-quartiles $\left(\mathrm{Q}_{25} ; \mathrm{Q}_{75}\right)$. All other numerical data is presented as mean \pm standard deviation (SD). Categorical data is presented as sum and percentage. Event rates have been analyzed and displayed using Kaplan-Meier-statistics.

To evaluate the effect of clinical and procedural factors on the TLR-rate a binary logistic regression analysis has been performed. The following criteria have been tested: age, sex, body-mass-index, history of arterial hypertension, diabetes, hyperlipidemia, nicotine abuse and renal failure, vessel status, left-ventricular ejection fraction, presence of cardiac shock, indication for index procedure, lesion localization, reference vessel diameter (RVD), lesion length, lesion type, stent diameter and length, treatment of unprotected left main stem, bifurcations, in-stent stenosis, acute myocardial infarction, aortocoronary ostial lesion, chronic total occlusion and saphenous vein graft, direct stenting, post-dilatation and interventional success. If a factor proved to be relevant, an odds ratio (OR) with a 95\% confidential interval (CI) has been calculated using a cross-table with a $\mathrm{Chi}^{2}$-test and a Mantel-Haenzel-Statistic.

\subsection{Definitions}

Arterial hypertension and diabetes have been defined according to current literature [4,5]. Myocardial infarction comprises Non-ST- (NSTEMI) and ST-elevation (STEMI) myocardial infarction as defined by current guidelines [6,7]. Cardiogenic shock was assumed when the systolic blood pressure had been less than $90 \mathrm{mmHg}$ and heart rate $>100 \mathrm{~min}^{-1}$ for more than 30 minutes requiring haemodynamic support by catecholamines and/or intraaortic counterpulsation [8]. A glomerular filtration rate as calculated by the Modification of Diet in Renal Disease (MDRD) formula of less than $60 \mathrm{ml} / \mathrm{min} / 1.73 \mathrm{~m}^{2}$ has been regarded as significant impairment of renal function [9].

Any cause of death that could not clearly be identified as non-cardiac has been regarded as cardiac, thus also including unknown causes of death.
Acute procedural success has been defined by treatment of the target lesion(s) with at least one Endeavor ${ }^{\mathrm{TM}}$ stent with a residual stenosis $<30 \%$ and no dissection greater than type B according to the National Heart Lung and Blood Institute criteria [10]. In-segment comprises everything from $5 \mathrm{~mm}$ proximal to $5 \mathrm{~mm}$ distal of the stented vessel, whereas the term in-stent refers to the stent section only.

Target lesion revascularization (TLR) comprises any new revascularization including PCI and bypass-surgery of the stented segment. In contrast, the term target vessel revascularization (TVR) represents any new revascularization including PCI and bypass-surgery of the treated vessel.

Major adverse cardiac event (MACE) is considered a composite endpoint of death, myocardial infarction, TLR and TVR.

\section{RESULTS}

\subsection{Baseline}

Patients' characteristics at baseline are summarized in Table 1. During the 2-year enrollment period of the study, 326 patients have been included into the registry. Fifty six percent (183) of the patients had previously "untouched" native coronary arteries. More than $80 \%$ of the patients had a two or three vessels disease. A small percentage of patients with severely reduced left ventricular function and even with cardiogenic shock had been included. Half of the patients presented with stable or unstable angina and almost one third of patients presented with myocardial infarction within 72 hours.

Table 2 summarizes the procedural characteristics of the treated patients. In total, 495 lesions had been treated during the initial procedure (mean $1.5 \pm 0.7$ per patient). In 355 vessels, $379(76.6 \%)$ of these lesions were treated with the use of the Endeavor ${ }^{\mathrm{TM}}$-Stent. The remaining lesions had been treated with bare-metal stents (BMS) or with balloon-angioplasty alone. No additional drug-eluting stent or drug-eluting balloon had been used.

The number of BMS per patient was $0.41 \pm 0.71$ with an average stent length of $(16.0 \pm 5.9) \mathrm{mm}$ and a stent diameter of $(3.3 \pm 0.5) \mathrm{mm}$. The brands that had been used were Driver $^{\mathrm{TM}}$ (Medtronic Corp., USA), Liberté ${ }^{\mathrm{TM}}$ (Boston Sci., USA) and Vision ${ }^{\mathrm{TM}}$ (Abbott Vascular, USA).

Almost $75 \%$ of all DES-treated lesions were type B2 or $\mathrm{C}$ lesions. The interventional success was high. There was a substantial number $(30 \%)$ of bifurcation lesions (i.e. involving a side-branch $\geq 1.5 \mathrm{~mm}$ ) among the treated lesions.

\subsection{Follow-up}

The median follow-up time was 35.3 months with an 
Table 1. Baseline data (SD—standard deviation, PCI-percutaneous coronary intervention, BMS - bare metal stent, DESdrug-eluting stent, $\mathrm{CABG}$ - coronary artery bypass graft, VDvessel disease, LVEF-left ventricular ejection fraction, MImyocardial infarction).

\begin{tabular}{ll}
\hline \multicolumn{1}{c}{ Number of patients } & \multicolumn{1}{c}{$326($ females 97, males 229$)$} \\
\hline Age (mean \pm SD) & $(67.5 \pm 10.3)$ years \\
Body mass index (mean \pm SD) & $(27.4 \pm 4.3) \mathrm{kg} / \mathrm{m}^{2}$ \\
Arterial hypertension & $271(83 \%)$ \\
Diabetes mellitus & $104(32 \%)$ \\
Dyslipoproteinemia & $265(81 \%)$ \\
Current smoker & $106(33 \%)$ \\
Renal failure & $51(16 \%)$ \\
& $203(62 \%)$ none \\
& $29(9 \%)$ balloon-angioplasty only \\
& $85(26 \%)$ with BMS only \\
Previous PCI & $5(2 \%)$ with DES only \\
& $4(1 \%)$ with BMS and DES \\
Previous CABG & $46(14 \%)$ \\
Vessel disease & $62(19 \%)$ single-VD \\
& $127(39 \%)$ two-VD \\
Indication & $137(42 \%)$ three-VD \\
LVEF & $217(67 \%)$ LVEF $\geq 50 \%$ \\
& $90(27 \%)$ LVEF $\geq 25 \%$ and $<50 \%$ \\
& $19(6 \%)$ LVEF $<25 \%$ \\
& $9(3 \%)$ \\
& $81(25 \%)$ stable angina \\
& $92(25 \%)$ unstable angina \\
& $3(1 \%)$ MI $\leq 72$ hours \\
& $55(17 \%)$ silent ischemia \\
& $9(3 \%)$ other \\
\hline
\end{tabular}

interquartile range of $30.4-41.6$ months. At 12 months follow-up data of 324 patients (99.4\%) and at 24 months data from 315 patients $(96.6 \%)$ were available. The clinical events during follow-up after 12 and 24 months are summarized in Table 3. The mortality rate during complete follow-up was $9.5 \%$ with a cardiac mortality of $3.7 \%$. Myocardial infarction rate was $5.5 \%$, the TVR rate was $13.8 \%$ whereas the TLR rate was $9.2 \%$. This cumulated into a MACE-rate of $24 \%$ for the complete followup period (Figure 1 and Figure 2).

During follow-up 165 patients $(50.6 \%)$ had at least one repeated angiography. The median interval was 8.9 months with an interquartile range of 4.5 - 16.2 months. Indications for angiography were recurrent angina and/or suspected myocardial ischemia in 106 patients $(64.2 \%)$, myocardial infarction in 15 patients $(9.1 \%)$ and a scheduled control angiography or intervention in 44 patients (26.7\%). Figure 2 shows a summary of events during follow-up period.
Table 2. Interventional data of Endeavor ${ }^{\mathrm{TM}}$-Stent treated lesions (LM-left main stem, LAD-left anterior descending artery, LCX - left circumflex artery, RCA - right coronary artery, SD - standard deviation, DES - drug eluting stent, BMS - bare metal stent, $\mathrm{SVG}$ - saphenous vein graft, $\mathrm{SB}$ - side branch).

\begin{tabular}{|c|c|}
\hline No. of DES-treated lesions & 379 \\
\hline No. DES/patient (mean \pm SD) & $1.28 \pm 0.51$ \\
\hline DES/lesion $($ mean $\pm \mathrm{SD})$ & $1.12 \pm 0.32$ \\
\hline Localization of lesions & $\begin{array}{l}34(9 \%) \text { LM } \\
205(54 \%) \text { LAD } \\
65(17 \%) \text { LCX } \\
64(17 \%) \text { RCA } \\
11(3 \%) \text { SVG }\end{array}$ \\
\hline Lesion classification & $\begin{array}{l}12(3 \%) \text { Type A } \\
91(24 \%) \text { Type B1 } \\
188(50 \%) \text { Type B2 } \\
88(23 \%) \text { Type C }\end{array}$ \\
\hline Unprotected left main stem & $31(8 \%)$ \\
\hline Bifurcation lesion & $\begin{array}{l}112(30 \%) \text { total } \\
15(4 \%) \text { no dilation of SB } \\
85(22 \%) \text { ball. dil. of SB } \\
7(2 \%) \text { T-stenting } \\
5(1 \%) \text { crush-stenting }\end{array}$ \\
\hline In-Stent-Stenosis & $38(10 \%)$ \\
\hline Acute myocardial infarction & $101(27 \%)$ \\
\hline Aorto-coronary ostial lesion & $27(7 \%)$ \\
\hline Chronic occlusion & $22(6 \%)$ \\
\hline$>40 \mathrm{~mm}$ Stent length & $33(9 \%)$ \\
\hline Bypass lesion & $10(3 \%)$ \\
\hline Ref. vessel diam. (mean \pm SD) & $3.0 \pm 0.4 \mathrm{~mm}$ \\
\hline Lesion length (mean $\pm \mathrm{SD}$ ) & $20.2 \pm 10.0 \mathrm{~mm}$ \\
\hline Stent diameter $($ mean $\pm \mathrm{SD})$ & $3.1 \pm 0.4 \mathrm{~mm}$ \\
\hline Stent length (mean \pm SD) & $23.8 \pm 10.0 \mathrm{~mm}$ \\
\hline Direct stenting & $144(38 \%)$ \\
\hline Post-dilatation & $\begin{array}{l}200(53 \%) \text { none } \\
14(4 \%) \text { with smaller balloon } \\
159(42 \%) \text { with equal-sized balloon } \\
6(2 \%) \text { with larger balloon }\end{array}$ \\
\hline Interventional success & $373(98 \%)$ \\
\hline
\end{tabular}

In 35 of all 379 lesions (9.2\%) a TLR had been performed, $10(28.6 \%)$ with balloon-angioplasty alone 14 $(40.0 \%)$ received a different drug-eluting stent, $10(28.6 \%)$ underwent bypass-operation, and 1 patient $(2.9 \%)$ received a bare metal stent.

Dual antiplatelet therapy (DAPT) with clopidogrel and aspirin has been performed for a median of 26 weeks. Eighty-five percent of patients completed a DAPT of at least 90 days, whereas after 12 months $41 \%$ of all pa- 
Table 3. Clinical events during follow-up (MI-Myocardial infarction, Non-TV-Other than target vessel, TVR-Target vessel revascularization, TLR - Target lesion revascularization, MACE-Major adverse cardiovascular events).

\begin{tabular}{lcc}
\hline & 12 months (324 pts.) & 24 months $(315$ pts.) \\
\hline Overall Mortality & $19(5.8 \%)$ & $23(7.3 \%)$ \\
Cardiac Mortality & $10(3.1 \%)$ & $11(3.5 \%)$ \\
MI & $5(1.5 \%)$ & $13(4.1 \%)$ \\
Non-TV MI & $2(0.6 \%)$ & $6(1.9 \%)$ \\
TVR ( $=355)$ & $31(8.7 \%)$ & $44(12.4 \%)$ \\
TLR $(\mathrm{n}=379)$ & $23(6.1 \%)$ & $32(8.4 \%)$ \\
MACE & $46(14.1 \%)$ & $69(21.9 \%)$ \\
\hline
\end{tabular}

tients alive still were on DAPT.

There were two cases $(0.6 \%)$ of definite or likely stent thrombosis during follow-up according to the Academic Research Consortium (ARC) classification [11]. One patient suffered a fatal myocardial infarction 5 days after the initial procedure while he was on dual antiplatelet therapy with aspirin and clopidogrel. The second patient presented with a subacute stent thrombosis more than 800 days after the procedure while he was on aspirin monotherapy. An aggregation test to prove thrombozytes' function during the current antiplatelet therapy had not been performed in these two cases.

Logistic regression analysis regarding risk factors for TLR during follow-up revealed a significant influence of the treatment of aorto-coronary ostial lesions (OR 3.8, $95 \%$ CI $1.5-9.8)$ and the treatment of saphenous vein graft lesions (OR 3.9, 95\% CI 1.1 - 15.6).

\section{DISCUSSION}

Meanwhile, data from other Endeavor-trials providing more long-term-data and allowing a comparison with other drug-eluting stents have been published (long-term data of Endeavor I and II, Endeavor III-trial: Endeavor ${ }^{\mathrm{TM}}$ vs. Cypher ${ }^{\mathrm{TM}}$ (Cordis Corp., USA), Endeavor IV-trial: Endeavor $^{\mathrm{TM}}$ vs. TAXUS ${ }^{\mathrm{TM}}$ (Boston Sci., USA)). These trials show superiority against the DRIVER ${ }^{\mathrm{TM}}$ bare metal stent (Medtronic Corp., USA) and non-inferiority against other drug eluting stents with 9 - 12 months major adverse cardiovascular event (MACE) rate of about $7 \%-9 \%$ in selected patients with a superior safety profile $[1,2,12$, 13].

The safety and efficacy of the Endeavor ${ }^{\mathrm{TM}}$-Stent in a real-world scenario are currently been investigated by the E-Five Registry including more than 8300 patients with more than 10,000 lesions at 188 hospitals worldwide [14]. More than 2100 patients completed a 2-year follow-up [15]. Thus, it provides an overwhelming amount of data. However, there is still some need for an even small registry [16].

First, there is a complete independency from industrial sponsorship, which may have an influence on study results, as has been shown in previous analysis [17]. Second, in the E-Five registry in $95 \%$ of all treated lesions the Endeavor ${ }^{\mathrm{TM}}$-Stent was the only device used [14]. To our opinion, this does not represent daily practice, as not every lesion (e.g. in large vessels) needs to be treated by a drug-eluting stent [18-20]. Therefore, in our registry about one fourth of all lesions received bare-metal stents.

Naturally, the complexity of patients and lesions in

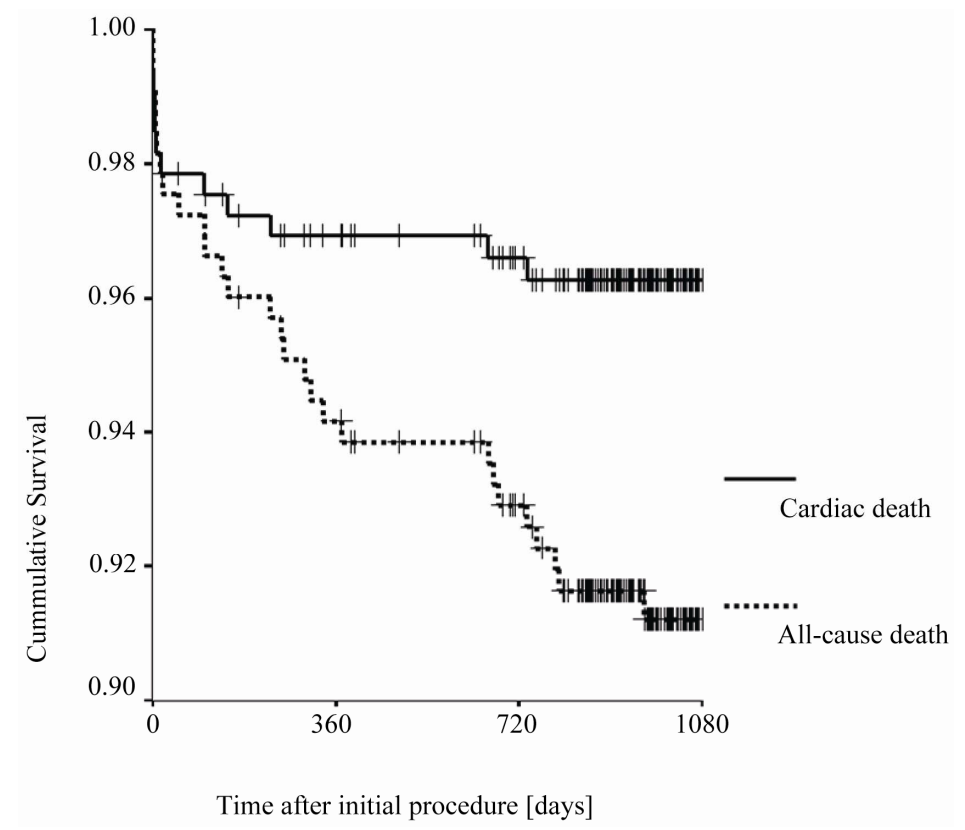

Figure 1. Kaplan-Meier-Curve comparing all-cause death rates and cardiac death rates during follow-up $\left({ }^{\dagger}\right.$-censored cases). 


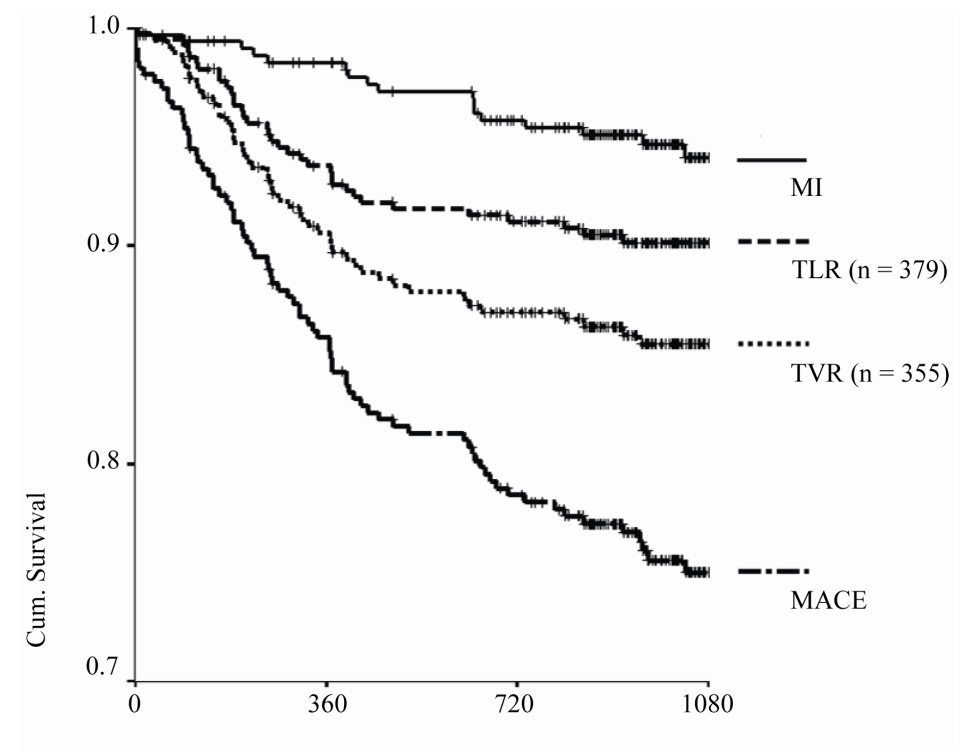

Time after initial procedure [days]

Figure 2. Kaplan-Meier-Curve comparing events during follow-up (MACE - major adverse cardiovascular events, MI-myocardial infarction, TLRtarget lesion revascularization, TVR - target vessel revascularization $\left({ }^{\dagger}-\right.$ censored cases).

controlled trials is somewhat different as compared to (daily-life) registries. In our registry, $73 \%$ of Endeavor ${ }^{\mathrm{TM}}$ treated lesions can be categorized as type $\mathrm{B} 2$ or $\mathrm{C}$ lesions. In the Endeavor II-trial $28 \%$ of all Endeavor ${ }^{\mathrm{TM}}$-treated lesions were classified as type C lesions, whereas $69 \%$ were type B1/2. However, bifurcation lesions, chronic occlusions, acute myocardial infarction etc. were excluded [1]. Hence, the complexity of our lesions has to be regarded as different from the Endeavor-II trial. In the E-Five Registry, about $60 \%$ of all lesions were classified as type $\mathrm{B} 2$ or $\mathrm{C}$ [14]. In other DES-registries it varied from 50\% (ARRIVE) to $86 \%$ (e-Cypher) [21,22].

The MACE rate during follow-up has significantly been influenced by non-cardiac events, underlining the co-morbidity of our patients. Still, the rate of $14 \%$ after 1 year and $21 \%$ after 2 years is higher in comparison to other DES-registries (e-Cypher: one year MACE rate 5.8\%, ARRIVE: one year MACE rate 9.5\%, two year rate $14.2 \%$, E-Five $7.5 \%$ and $8.5 \%$ ) [15,21,22]. These differences might be at least partially explained by different patients' characteristics at baseline: patients in our registry were up to 5 years older and the percentage of patients with recent myocardial infarction (i.e. $\leq 72$ hours previous to the procedure) were higher in our registry (29\% vs. $7 \%$ [e-Cypher] or $11 \%$ [E-Five, 2-year followup group]) [15,22]. Also, slightly different definitions of the composite endpoint "MACE" may have contributed to different results [11]. In our data, roughly $50 \%$ of the observed myocardial infarctions during one and two years of follow-up have been caused by non-target ves- sels.

The TLR rate has been comparable to the E-Five registry (2 year TLR rate 5.1\%) and the ARRIVE registry (2 year TLR rate $7.3 \%$ ) [15,21]. The long-term data of the ENDEAVOR-II trial revealed a 5-year TLR rate of 7.5\% for the Endeavor-Stent (vs. 16.3\% for the BMS group) [1]. Mauri et al. published a meta-analysis including 6 randomized trials comparing the Endeavor ${ }^{\mathrm{TM}}$-Stent to BMS with more than 2.100 patients: After 5 years the TLR-rate for the Endeavor ${ }^{\mathrm{TM}}{ }_{\text {-Stent }}$ was $7.0 \%$ (vs. $16.5 \%$ for the BMS) and the overall mortality rate $5.9 \%$ (vs. $7.6 \%$ for BMS) [24]. The SORT OUT III trial revealed an 18 -month TLR rate of $6 \%$ (vs. $2 \%$ for the sirolimuseluting stent), however it did not really represent an "allcomers" trial, as more than $50 \%$ of the eligible patients had not been included [23]. Recently published data from the KOMER AMI trial, comparing the Endeavor ${ }^{\mathrm{TM}}{ }_{-}$Stent with paclitaxel- and sirolimus-eluting stents in acute STelevation myocardial infarction, reported a target vessel failure of $15 \%$ for the Endeavor ${ }^{\mathrm{TM}}$-Stent after two years, which did not differ significantly from the other stents [25].

Treatment of aorto-coronary ostial lesions and saphenous vein grafts could be identified as risk factor for TLR in our registry. The higher re-intervention rate in bypass grafts has been demonstrated in previous trials also for different drug-eluting stents [26]. Due to various (patho-) anatomical reasons interventional treatment of aorto-coronary ostial lesions is associated with a higher restenosis rate. Iakovou et al. reported angiographic res- 
tenosis rates of $51 \%$ in bare metal stents vs. $11 \%$ in sirolimus drug-eluting stents in the treatment of aortoostial lesions [27]. Recently, Luz et al. published a TLR -rate of $13 \%$ with no significant difference between BMS vs. DES [28]. Other trials detected additional risk factors for restenosis, such as male gender [29].

Although one cannot exclude an underreporting of events, the rate of definite or likely stent thrombosis during follow-up is consistent with the Endeavor-II-trial $(0.5 \%)$, the E-Five registry $(0.7 \%$ after two years) and other trials (ISAR-Test 2: $0.6 \%$, Wenaweser et al. $0.4 \%$ $0.6 \%$ per year) and emphasizes the safety of the Endeavor $^{\mathrm{TM}}$-Stent in clinical practice $[1,15,30,31]$. This has also been demonstrated in direct comparison against the Taxus $^{\mathrm{TM}}$ - and the Cypher ${ }^{\mathrm{TM}}$-Stent $[12,13]$. Recently, it has been proven, that the Endeavor ${ }^{\mathrm{TM}}$-Stent showed better endothelial strut coverage even in myocardial infarction in comparison to other DES [32-34]. However, the SORT OUT III trial revealed a low (1\%) but significantly higher rate of definite stent-thrombosis after nine months in comparison to sirolimus-eluting stents [23].

The optimal duration of dual antiplatelet therapy (DAPT) still remains controversial. In low-risk patients a time period of 3 months after implantation of an Endeavor ${ }^{\mathrm{TM}}$ seems feasible, however the books on this topic have not been closed yet [35].

\section{Limitations}

This is a single-center registry and the number of patients is very limited in comparison to other registries. As a consequence the number of events in this population might have been too small to detect certain correlations. There is no control group (e.g. with another drug-eluting stent). In addition, an independent review- and monitoring board has not been involved. Therefore, a certain investigator bias cannot be excluded as well as over- or underreporting of events.

\section{CONCLUSION}

The Endeavor ${ }^{\mathrm{TM}}$-Stent is a safe and effective drug-eluting stent in the treatment of daily-life coronary patients even with acute myocardial infarctions. The treatment of saphenous-vein grafts and aorto-coronary ostial lesions appears to be associated with a higher need for re-interventions in these patients.

\section{ACKNOWLEDGEMENTS}

K. H. thanks Liana Hertting for her inexhaustible support and encouragement.

\section{REFERENCES}

[1] Fajadet, J., Wijns, W., Laarman, G.J., et al. (2010) Long-
Term follow-up of the randomised controlled trial to evaluate the safety and efficacy of the zotarolimus-eluting driver coronary stent in de novo native coronary artery lesions: Five year outcomes in the ENDEAVOR II study. EuroIntervention, 6, 562-567.

[2] Meredith, I.T., Ormiston, J., Whitbourn, R., et al. (2009) Five-Year clinical follow-up after implantation of the Endeavor zotarolimus-eluting: ENDEAVOR I, first-in-human study. Catherization and Cardiovascular Interventions, 74, 989-995. doi:10.1002/ccd.22206

[3] Ryan, T.J., Faxon, D.P., Gunnar, R.M., et al. (1988) Guidelines for percutaneous transluminal coronary angioplasty. A report of the American College of Cardiology/American Heart Association task force on assessment of diagnostic and therapeutic cardiovascular procedures (subcommittee on percutaneous transluminal coronary angioplasty). Circulation, 78, 486-502. doi:10.1161/01.CIR.78.2.486

[4] Mancia, G., De Backer, G., Dominiczak, A., et al. (2007) Guidelines for the management of arterial hypertension. European Heart Journal, 28, 1462-1536. doi:10.1093/eurheartj/ehm236

[5] Rydén, L., Standl, E., Bartnik, M., et al. (2007) Guidelines on diabetes, pre-diabetes, and cardiovascular diseases: Executive summary: The Task Force on Diabetes and Cardiovascular Diseases of the European Society of Cardiology (ESC) and of the European Association for the Study of Diabetes (EASD). European Heart Journal, 28, 88-136.doi:10.1093/eurheartj/ehl260

[6] Van de Werf, F., Bax, J., Betriu, A., et al. (2008) Management of acute myocardial infarction in patients presenting with persistent ST-segment elevation. European Heart Journal, 29, 2909-2945. doi:10.1093/eurheartj/ehn416

[7] Bassand, J.P., Hamm, C.W., Ardissino, D., et al. (2007) Guidelines for the diagnosis and treatment of non-STsegment elevation acute coronary syndromes. European Heart Journal, 28, 1598-1660. doi:10.1093/eurheartj/ehm161

[8] Hochman, J.S., Sleeper, L.A., White, H.D., et al. (2001) One-year survival following early revascularization for cardiogenic shock. Journal of the American Medical Association, 285, 190-192. doi:10.1001/jama.285.2.190

[9] Levey, A.S., Coresh, J., Balk, E., et al. (2003) National Kidney Foundation practice guidelines for chronic kidney disease: Evaluation, classification, and stratification. Annals of Internal Medicine, 139, 137-147.

[10] Biondi-Zoccai, G.G., Agostoni, P., Sangiorgi, G.M., et al. (2006) Incidence, predictors, and outcomes of coronary dissections left untreated after drug-eluting stent implantation. European Heart Journal, 27, 540-546. doi:10.1093/eurheartj/ehi618

[11] Cutlip, D.E., Windecker, S., Mehran, R., et al. (2007) Clinical end points in coronary stent trials: A case for standardized definitions. Circulation, 115, 2344-2351. doi:10.1161/CIRCULATIONAHA.106.685313

[12] Kandzari, D.E., Mauri, L., Popma, J.J., et al. (2011) Late-Term clinical outcomes with zotarolimus- and sirolimus-eluting stents. 5-year follow-up of the EN- 
DEAVOR III (a randomized controlled trial of the medtronic endeavor drug [ABT-578] eluting coronary stent system versus the cypher sirolimus-eluting coronary stent system in de novo native coronary artery lesions). Journal of the American College of Cardiology Cardiovascular Interventions, 4, 543-550.

[13] Leon, M.B., Nikolsky, E., Cutlip, D.E., et al. (2010) Improved late clinical safety with zotarolimus-eluting stents compared with paclitaxel-eluting stents in patients with de novo coronary lesions: 3-year follow-up from the ENDEAVOR IV (randomized comparison of zotarolimusand paclitaxel-eluting stents in patients with coronary artery disease) trial. Journal of the American College of Cardiology Cardiovascular Interventions, 3, 1043-1050.

[14] Lotan, C., Meredith, I.T., Mauri, L., et al. (2009) Safety and effectiveness of the Endeavor zotarolimus-eluting stent in real-world clinical practice: 12-month data from the E-Five registry. Journal of the American College of Cardiology Cardiovascular Interventions, 2, 1227-1235.

[15] Meredith, I., Rothman, M., Erglis, A., et al. (2011) Extended follow-up safety and effectiveness of the Endeavor zotarolimus-eluting stent in real-world clinical practice: Two-Year follow-up from the E-five registry. Catherization and Cardiovascular Interventions, 77, 9931000. doi: $10.1002 / \mathrm{ccd} .22803$

[16] Mukherjee, D., Moliterno, D.J. (2009) Second-Generation drug-eluting stents and the continuous need for rapidly available real-world data. Journal of the American College of Cardiology Cardiovascular Interventions, 2, 1236-1239.

[17] Ligthart, S., Vlemmix, F., Dendukuri, N., Brophy, J.M. (2007) The cost-effectiveness of drug-eluting stents: A systematic review. Canadian Medical Association Journal, 176, 199-205. doi:10.1503/cmaj.061020

[18] Wijns, W., Kolh, P., Danchin, N., et al. (2010) Guidelines on myocardial revascularization. European Heart Journal, 31, 2501-2555.

[19] Steinberg D.H., Mishra S., Javaid A., et al. (2007) Comparison of effectiveness of bare metal stents versus drugeluting stents in large $(\geq 3.5 \mathrm{~mm})$ coronary arteries. American Journal of Cardiology, 99, 599-602. doi:10.1016/j.amjcard.2006.09.105

[20] Yan, B.P., Ajani, A.E., New, G., et al. (2008) Are drugeluting stents indicated in large coronary arteries? Insights from a multi-centre percutaneous coronary intervention registry. International Journal of Cardiology, 130, 374-379. doi:10.1016/j.ijcard.2008.06.046

[21] Lasala, J.M., Cox, D.A., Lewis, S.J., et al. (2009) Expanded use of the TAXUS Express stent: Two year safety insights from the 7500 patients ARRIVE Registry program. EuroIntervention, 5, 67-77.

[22] Urban, P., Gershlick, A.H., Guaglium,i G., et al. (2006) Safety of coronary sirolimus-eluting stents in daily clinical practice. One-year follow-up of the e-Cypher registry. Circulation, 113, 1434-1441. doi:10.1161/CIRCULATIONAHA.104.532242

[23] Rasmussen, K., Maeng, M., Kaltoft, A., et al. (2010) Efficacy and safety of zotarolimus-eluting and sirolimuseluting coronary stents in routine clinical care (SORT
OUT III): A randomized controlled superiority trial. Lancet, 375, 1090-1099. doi:10.1016/S0140-6736(10)60208-5

[24] Mauri, L., Massaro, J.M., Jiang, S., et al. (2010) LongTerm clinical outcomes with zotarolimus-eluting versus bare-metal coronary stents. Journal of the American College of Cardiology Cardiovascular Interventions, 3, 12401249.

[25] Kang, W.C., Ahn, T., Lee, K., et al. (2011) Comparison of zotarolimus-eluting stents versus sirolimus-eluting stents versus paclitaxel-eluting stents for primary percutaneous coronary intervention in patients with ST-elevation myocardial infarction. EuroIntervention, 7, 936-943.

[26] Zahn, R., Hamm, C.W., Schneider, S., et al. (2005) Incidence and predictors of target vessel revascularization and the clinical event rates of the sirolimus-eluting coronary stent (results from the proscective multicenter German cypher stent registry). American Journal of Cardiology, 95, 1302-1308. doi:10.1016/j.amjcard.2005.01.072

[27] Iakovou, I., Ge, L., Michev, I., et al. (2004) Clinical and angiographic outcome after sirolimus-eluting stent implantation in aorto-ostial lesions. Journal of the American College of Cardiology, 44, 967-971. doi:10.1016/j.jacc.2004.05.058

[28] Luz, A., Hughes, C., Magalhães, R., et al. (2011) Stent implantation in aorto-ostial lesions: Long-Term follow-up and predictors of outcome. EuroIntervention, 7, 10691076.

[29] Nakatani, D., Ako, J., Tremmel, J.A., et al. (2011) Sex differences in neointimal hyperplasia following endeavor zotarolimus-eluting stent implantation. American Journal of Cardiology, 108, 912-917. doi:10.1016/j.amjcard.2011.05.019

[30] Byrne, R.A., Kastrati, A., Tiroch, K., et al. (2010) 2-year clinical and angiographic outcomes from a randomized trial of polymer-free dual drug-eluting stents versus polymer-based Cypher and Endeavor, drug eluting stents. Journal of the American College of Cardiology, 55, 2536- 2543. doi:10.1016/i.jacc.2010.03.020

[31] Wenaweser, P., Daemen, J., Zwahlen, M., et al. (2008) Incidence and correlates of drug-eluting stent thrombosis in routine clinical practice. 4-year results from a large 2institutional cohort study. Journal of the American College of Cardiology, 52, 1134-1140. doi:10.1016/i.jacc.2008.07.006

[32] Fan, C., Kim, J.S., Lee, J.M., et al. (2010) Different vascular healing patterns with various drug-eluting stents in primary percutaneous coronary interventions for STsegment elevation myocardial infarction: Optical coherence tomographic findings. American Journal of Cardiology, 105, 972-976. doi:10.1016/j.amjcard.2009.11.018

[33] Kim, J.S., Jang, I.K., Fan, C., et al. (2009) Evaluation in 3 months duration of neointimal coverage after zotarolimus-eluting stent implantation by optical coherence tomography: The ENDEAVOR OCT trial. Journal of the American College of Cardiology Cardiovascular Interventions, 2, 1240-1247.

[34] Li, S., Wang, Y., Gai, L., et al. (2011) Evaluation of neointimal coverage and apposition with various drug-eluting 
stents over 12 months after implantation by optical coherence tomography. International Journal of Cardiology. doi:10.1016/j.ijcard.2011.05.076

[35] Hahn, J.Y., Song, Y.B., Choi, J.H., et al. (2010) Threemonth dual antiplatelet therapy after implantation of zo- tarolimus-eluting stents: The DATE (duration of dual antiplatelet therapy after implantation of endeavor stent) registry. Circulation Journal, 74, 2314-2321. doi:10.1253/circj.CJ-10-0347 